\title{
Notas sobre a voz causativa-comitativa em Kaiowá e Guajajára
}

\author{
Notes on the causative-comitative voice in \\ Kaiowá and Guajajára
}

Rosileide Barbosa de Carvalho ${ }^{1}$

Marina Cintia da Silva Guajajára ${ }^{2}$

DOI: https://doi.org/10.26512/rbla.v10i2.20982

Recebido em setembro de 2018

Aceito em outubro de 2018

\begin{abstract}
Resumo
Focaliza-se a expressão da voz causativa-comitativa em Kaiowá e em Guajajára, uma das cinco expressões de voz típicas da família Tupí-Guaraní. A análise da voz causativacomitativa nessas duas línguas foi inspirada em Rodrigues (1953), o linguista que descreveu pela primeira vez e apropriadamente a função do morfema cognato em uma língua TupíGuaraní, o Tupinambá. No presente estudo, mostramos que o morfema causativo-comitativo em Kaiowá e em Guajajára possui mais alomorfes do que o reportado até o presente nos estudos sobre essas duas línguas. Como descrito em Barbosa (2017), o morfema causativocomitativo em Kaiowá possui 11 alomorfes: ero-, ro-, no-, era-, ra-, er-, r-, gwer-, gwero-, gwera-, gweno-; já o causativo-comitativo em Guajajára possui 9 alomorfes: eru-, ru-, enu-, era-, ra-, er-, r-, wera-, weru-. A alomorfia do morfema causativo Kaiowá e do Guajajára deve ser considerada na documentação e descrição linguística que se quer voltada para o fortalecimento do uso dessas línguas.
\end{abstract}

Palavras-chave:. Guajajára. Kaiowá. Tupí-Guaraní. Voz. Causativo-comitativo. Alomorfia.

\begin{abstract}
The expression of the causative-comitative voice in Kaiowá and Guajajára is described. It is one of the five typical Tupi-Guarani voice expressions. The analysis of the causativecomitative voice in these two languages was inspired by Rodrigues (1953), the linguist who described for the first time and properly the function of the cognate morpheme in a Tupi-Guaraní language, Tupinambá. In the present study, we have shown that the causativecomitative morpheme in Kaiowá and Guajajára has more allomorphs than the ones reported to date in the studies on these two languages. As described in Barbosa (2017), the causativecomitative morpheme in Kaiowá has 11 allomorphs: ero-, ro-, no-, era-, ra-, er-, r-, gwer-, gwero-, gwera-, gweno -; already the causative-comitative in Guajajára has 9 allomorphs: eru-, ru-, enu-, era-, ra-, er-, r-, wera-, weru-. The allomorphism of the Kaiowá and the Guajajára causative-comitative morpheme must be considered in the documentation and

\footnotetext{
${ }^{1}$ Doutoranda no Programa de Pós-Graduação em Linguística da Universidade de Brasília.

${ }^{2}$ Mestranda no Programa de Pós-Graduação em Linguística da Universidade de Brasília.
} 
linguistic description that is aimed at strengthening the use of these languages.

Keywords: Guajajára. Kaiowá. Tupí-Guaraní. Voice. Causative-comitative. Alomorphy.

\section{Um pouco de história}

Tratamos aqui de alguns dos resultados de nossa pesquisa linguística sobre a expressão de voz em nossas respectivas línguas maternas, o Kaiowá e o Guajajára. A língua Kaiowá é uma das línguas que integram o subramo I da família linguística Tupí-Guaraní, subramo este também conhecido como subramo Guaraní. A língua Guajajára, por sua vez, pertence ao subramo IV da mesma família linguística (Rodrigues 1984-1985). A língua Kaiowá é falada em reservas, fazendas, acampamentos e em comunidades de periferias de cidades, localizadas no estado do Mato Grosso do Sul. O Guajajára é falado em oito Terras Indígenas (TI), distribuídas em oito municípios, no Estado do Maranhão - TI Araribóia (Amarante, Grajaú e Santa Luzia), TI Morro Branco (Grajaú), TI Pindaré (Bom Jardim e Monção), TI Bacurizinho (Barra do Corda e Grajaú), TI Caru (Municio de Bom Jardim), TI Governador (Amarante), TI Krikatí (Amarante, Morros Altos e Sítio novo), TI Lagoa Comprida (Barra do Corda), TI Morro Branco (Grajaú), TI Rodeador (Barra do Corda) TI UrucuJuruá (Grajaú). Os Kaiowá somam aproximadamente 44.000 indivíduos e os Guajajára, juntamente com os Tembé são aproximadamente 26.000 indivíduos.

Apesar da distância geográfica entre os Kaiowá e os Guajajára, as duas línguas compartilham vários traços de interesse para os estudos históricocomparativos da família Tupí-Guaraní. Focalizamos aqui a expressão da voz causativa-comitativa, que é uma das cinco expressões de voz encontradas em Kaiowá e em Guajajára, típicas da família Tupí-Guaraní. A análise da voz causativa-comitativa nessas duas línguas foi inspirada em Rodrigues (1953), o linguista que descreveu pela primeira vez e apropriadamente a função do morfema cognato em uma língua Tupí-Guaraní, o Tupinambá. A voz causativacomitativa no Tupinambá, segundo Rodrigues (1953, p.136), é aquela em que:

o sujeito faz outrem exercer a ação, praticando-a ele também; portanto o sujeito e o objeto direto praticam ação conjuntamente, em companhia, sendo ambos agentes imediatos. (Rodrigues 1953:136)

Ao conceber o morfema ero- do Tupinambá como expressão da voz causativa-comitativa, Rodrigues acentuou a associação de uma mudança de valência, naturalmente com implicações sintáticas, bem como a função comitativa do morfema. Essa associação têm-se mostrado fundamental em descrições que procuram dar conta das funções linguísticas como expressões dos modo de ser dos povos Tupí. E o "fazer junto" é fundamental para os povos Kaiowá e Guajajára. A voz causativo-comitativa em Kaiowá e em Guajajára 
apresenta-se como em Tupinambá, exceto quanto ao fato de que neste último, o morfema causativo-comitativo além de combinar-se com verbos intransitivos, combinava-se também com nomes. No Kaiowá e no Guajajára, esta combinação não foi atestada.

Dos estudos linguísticos sobre o Kaiowá, Cardoso (2008) descreve dois alomorfes para o morfema causativo-comitativo Kaiowá, -gwere $\sim$-re que se combinam com o verbo ko. A autora considera esse morfema pouco produtivo em relação aos outros dois morfemas causativos do Kaiowá, os morfemas mo- 'causativo simples' e -uka 'causativo prepositivo'. Mejia (2017: 98-99) descreve quatro alomorfes para o morfema 'causativo-comitativo' do Kaiowá: era-, ra-, er-, $r$-.

Quanto aos estudos linguísticos sobre o Guajajára, Harrison e Harrison (2013), embora apresentem exemplos com alguns alomorfes do morfema em pauta, põem em evidência como informação na segmentação dos exemplos das entradas do Dicionário da Língua Guajajára, o alomorfe eru-. Castro (2013) e Camargos (2017) tratam o morfema causativo-comitativo como morfema aplicativo, à luz da Morfologia Distribuída. Seguindo Halle \& Marantz (1993), Harley \& Noyer (1997, 1999), Camargos parte do princípio de que "as formações de palavras e de sentenças são vistas como o produto de um mesmo mecanismo derivacional sintático, constituindo-se, por consequência, como uma proposta derivacional não lexicalista.”(p. 35). Silva (2014), segue a análise de Rodrigues para o Tupinambá e demais línguas da Família Tupí-Guaraní, tratando o morfema causativo-comitativo como um morfema derivacional ativo na formação de verbos transitivos a partir de verbos intransitivos, modificando, assim, a valência original do verbo base da derivação. Silva (p. 680-681) apresenta o morfema causativo comitativo do Guajajára como tendo quatro alomorfes - eru-, er, e ru- nu--; já Camargos (2017) e Castro (2013) apresentam uma única forma do desse morfema.

Ressaltamos que, em alguns dialetos Guajajára, começam a surgir raros exemplos de combinação do morfema causativo-comitativo com verbos transitivos, mas que correspondem a uso eventual na fala de poucos indivíduos.

\section{A riqueza alomórfica do morfema causativo}

No presente estudo, mostramos que o morfema causativo em Kaiowá e em Guajajára possui mais alomorfes do que o reportado até o presente nos estudos sobre essas duas línguas. Em Kaiowá, segundo Barbosa (2017), o morfema causativo possui 11 alomorfes, como reiterado aqui : ero-, ro-, no-, era-, ra-, er-, r-, gwer-, gwero-, gwera-, gweno-; já o causativo-comitativo em Guajajára possui 9 alomorfes: eru-, ru-, enu-, era-, ra-, er-, r-, wera-, weru-. Nas duas línguas esses alomorfes são bem distribuídos e produtivos.

Apresentamos, em seguida, exemplos ilustrativos dos contextos em que se 
dão os usos dos alomorfes do morfema causativo-comitativo em Kaiowá e em Guajajára.

\section{O alomorfe ero-}

Kaiowá

1) a-ero-sẽ

1-CC-sair

'eu o/a faço/fiz sair no terreiro comigo'

2) ere-ero-sẽ oka-pe

2-CC-sair terreiro-LOC

'você o/a faz/fez sair no terreiro com vocês'

3) oro-ero-sẽ oka-pe

1excl-CC-sai terreiro-LOC

'nós o/a fazemos/fizemos sair no terreiro conosco'

4) pe-ero-sẽ

$2 \mathrm{p}$-CC-sai'

'vocês o/a fazem/fizeram sair com vocês'

5) o-ero-sẽ

3- CC-sai'

'ele o/a faz/fez sair no terreiro consigo'

Guajajára

6) kuzà w-eru-ata u-memyr a'e mulher 3-CC-andar 3-filho(a) esse

'a mulher anda levando seu filho'

7) tuwihaw w-eru-ze'eg-atu w-emi-aihu wə

chefe 3-CC-falar-bem 3CORR-NOM-amar 3PL

'o chefe aconselha bem o seu povo' (Harrison e Harrison 2013:213)

Este último exemplo ilustra nuances semânticas do morfema causativocomitativo em Guajajára. Aconselhar, nessa língua, não é apenas falar bem, mas fazer com que o ouvinte fale bem com alguém. Aconselhar já inclui o ouvinte como sujeito da ação. 


\section{O alomorfe -ro}

Kaiowá

8) a-ro-ike nde xe $\varnothing$-ndiwe

1-CC-entrar $2 \quad 1 \quad \mathrm{R}^{1}$-ASSOC

'eu faço/fiz você entrar comigo'

9) re-ro-wa nde mena ne $\varnothing$-ndiwe

2-CC-mudar 2 marido $2 \quad \mathrm{R}^{1}$-ASSOC

'você faz/fez seu marido mudar com você'

10) o-ro-wa nde xe $\varnothing$-ndiwe

3-CC-mudar $2 \quad 1 \quad \mathrm{R}^{1}$-ASSOC

'ele fizeram vocês mudarem comigo'

Guajajára

11) u-ze-ru-kwahy-kar Milton ywyrá i-puhyj pe

3-ref-cC-doença-prep Milton madeira' $\mathrm{R}^{2}$-pesado dat

'Milton se fez adoecer pelo peso da madeira'

12) ere-ru-hem 'y amokatú-pe

2-CC-sair água lá.fora-loc

'você derrama a água lá fora (saindo com ela)'

13) a-ru-itfe amo teko uken-pe

1-CC-entrar uma pessoa porta-loc

'eu fiz entrar uma pessoa na porta (pela)'

\section{Alomorfe -gwer}

Kaiowá

14) a-gwer-u xe $\varnothing$-ndiwe

1-CC-vir $1 \quad \mathrm{R}^{1}$-ASSOC

'eu o/a faço/fiz vim comigo'

15) ere-gwer-u ne $\varnothing$-ndiwe

2-CC-vir $2 \quad \mathrm{R}^{1}$-ASSOC

'você o/a faz/fez vir com você' 
16) oro-gwer-u a-py

1excl-cC-vir este-loc

'nós o/a fazemos/fizemos vir conosco aqui'

17) o-gwer-u a-py

3-CC-vir este-loc

'ele fêz/faz vir Guajajára

Não foi encontrado em Guajajára cognato do alomorfe gwer- do Kaiowá.

\section{O alomorfe -gwera}

Kaiowá

18) a-ipyhy i-jywa r-e a-gwera-ha

1-pegar $\mathrm{R}^{2}$-braços $\mathrm{R}^{2}$-REL ir-CC-ir

'eu seguro/segurei nos braços dele/dela e o/a faço/fiz ir comigo'

19) ere-gwera-ha ne $\varnothing$-NDIWE

2-CC-Vir $\quad 2 \quad \mathrm{R}^{1}$-ASSOC

'você o/a faz /fez ir com você' ou 'você o/a leva/levou com você'

20) xe $\varnothing$-gwera-ha ne $\varnothing$-ndiwe

$1 \quad \mathrm{R}^{1}$-CC-ir $\quad 2 \quad \mathrm{R}^{1}$-ASSOC

'você me leva/levou com você'

21) o-ipyhy i-jywa r-e a-gwera-ha-wy

3p-pegar $\quad \mathrm{R}^{2}$-braços $\quad \mathrm{R}^{2}$-rel ir-CC-ir-GER

'ele segurou no braço e o fez ir consigo'

Guajajára

22) he $\varnothing$-wera-ha

$1 \quad \mathrm{R}^{1}$-CC-ir

'levarm-me consigo'

\section{O alomorfe gwero-}

Kaiowá

23) ere-gwero-ike nde Ø-mena ne $\varnothing$-ndiwe 2-CC-entrar $2 \quad \mathrm{R}^{1}$-marido $2 \quad \mathrm{R}^{1}$-ASSOC

'você faz/fez seu marido entrar com você' 
24) pe-gwero-mo-sẽ ko'ãnga

2pl-cC-sair agora

'voces o fez sair consigo agora' ' voces a faz sair consigo agora'

O alomorfe wer- $\sim$ er-

Guajajára

25) u-wer-uwak

3-CC-virar

'ele o/a faz virar-se consigo'

26) a-wer-uak

1-CC-virar

'eu o/a faço virar-se comigo'

27) w-er-uwak kwaharer zawazyr ita iwy-pe a'e wà

3-CC-vira-se menino escorpião pedra embaixo-LoC esse $3 \mathrm{pl}$

'os meninos procuravam escorpiões virando pedras' (Harrison e Harrison 2013:183)

\section{O alomorfe no-}

Kaiowá

28) ere-no-hẽ-rõ jety e-h-esy

$2 \mathrm{p}$-CC-sair-COND batata doce $2 \mathrm{p}-\mathrm{R}^{2}$-assar

'voce fez sair a batata doce para você assar'

29) pe-no-hẽ-rõ jety pe-mo-mimõi

2p-CC-sair-COND batata doce 2p-CC-cozer'

'voces fizeram sair batata doce para voces cozinharem'

30) o-no-hẽ-rõ jety e-h-esy

3-CC-sair-COND batata doce 2- $\mathrm{R}^{2}$-assar

'eles fizerem sair batata doce e você assou'

\section{O alomorfe gueno-}

Kaiowá

31) a-gweno-hẽ 'y-gwi mitã 1-CC-sair água-ABL criança

'eu faço sair a criança da água' 
32) ere-gweno-hẽ y-gwi

2-CC-sair água-ABL

'você o fez sair água'

33) já-gweno-hẽ y-gwi

1 INCL-CC-sair água água-ABL

'nós o fazemos sair da água'

34) o-gweno-hẽ $\quad$-gwi

3-CC-sair água-ABL

'ele fez sair água'

\section{O alomorfe enu-}

Guajajára

35) w-enu-hem h-era-ha

3-CC-sair $\quad \mathrm{R}^{2}$-CC-ir

'ele o/a fez sair e o/a levou consigo'

\section{O alomorfe ra-}

Kaiowá

36) a-ra-ha nde h-egwi ne Ø-mena

1-CC-ir $2 \quad \mathrm{R}^{2}$-ABL $2 \quad \mathrm{R}^{1}$-marido

'eu levo de você, o seu marido'

37) ere-ra-ha nde h-egwi po'y

2-CC-ir 2 R ${ }^{2}$-ABL $\quad$ colar

'voce leva dele, o colar'

38) oro-ra-ha xugwi i-jagwa

1excl-CC-ir 3.ABL $\mathrm{R}^{2}$-cachorro

'nós faz o cachorro ir dele' 'nós faz o cachorro ir dele'

39) o-ra-ha nde-wy kagwĩ

3-CC-ir 2-DAT sopa

'levou a sopa com ele para você' 
Guajajára

40) a-ra-ha ne r-apyj-pe

1-CC-ir $2 \quad \mathrm{R}^{1}$-casa-LOC

'eu o/a levo na sua casa'

41) a-ra-ha maper

1-CC-ir papel

'eu levei papel'

42) t ti-ra-ha maper

lincl-cC-ir papel

'nós (incl.) levamos papel'

43) uru-ra-ha maper

1excl-cC-ir papel

'nós(excl.) levamos papel'

\section{O alomorfe era-}

Kaiowá

44) Maria o-i-pyhy h-era-ha-wy i-mena

Maria 3- $\mathrm{R}^{2}$-pegar $\quad \mathrm{R}^{2}$-CC-ir-GER $\quad \mathrm{R}^{2}$-marido

'Maria segurou o marido dela e o fez ir consigo'

45) kuña o-i-pyhy mbayru=ndururu h-era-ha-wy mulher 3- $\mathrm{R}^{2}$-pegar condução=rolar $\quad \mathrm{R}^{2}$-CC-ir-GER 'a mulher pegou a bicicleta e a levou consigo'

46) tagwato o-i-pyhy rygwasu ogw-era-ha-wy gavião 3- ${ }^{2}$-pegar galinha 3-CC-ir-GER 'gavião agarrou a galinha e a fez ir consigo'

Guajajára

47) w-era-ha-paw

3-CC-ir-COMPL

'ele leva/levou tudo'

48) w-era-ha tuira u-memyr

3-CC-ir Tuira 3CORR-filho(a)

'Tuira levou seu filho consigo' 


\section{O alomorfe $r$ -}

Kaiowa

49) a-r-u xe pehẽngue

1-CC-vir 1 família

'eu trago/trouxe minha família 'ou 'eu faço/fiz vir minha família comigo'

50) ere-r-u ao-potĩ

2-CC-vir roupa-limpa

'voce trouxe/trago roupa limpa'

51) pe-r-u moã i-xupe

2-CC-vir FRUST $\mathrm{R}^{2}$-DAT

'voces iá fazer ele vir'

52) o-r-u y ne $\varnothing$-ndiwe

3-CC-vir água $2 \quad \mathrm{R}^{1}$-ASSOC

'ele traz/trouxe água com voce'

Guajajára

53)

$\begin{array}{llllll}\text { a-r-ur putar } & \text { t-emi-'u } & \text { pixik } & \text { pe-me } & \text { nehe } & \text { no } \\ \text { 1-CC-ir poder } & \mathrm{R}^{4} \text {-NOM-ingerir } & \text { pouco } & \text { 2pl-dat } & \text { inten } & \text { novamente } \\ \text { nezewe } & \text { mehe } & \text { pe-kàgaw } & \text { u-zewyr putar } & \text { pe-me } & \text { nehe } \\ \text { assim } & \text { SUB } & \text { 2pl-força } & \text { 3-voltar bem } & \text { 2pl-dar } & \text { INTEN }\end{array}$

'também vou trazer um pouco de comida, e assim as suas forças vão voltar'

(Harrison e Harrison 2013:121)

\section{A importância de uma descrição linguística detalhada}

Mostramos nestas notas que os morfema causativo-comitativo do Kaiowá e o do Guajajára são bastante produtivos e que ambos possuem uma rica alomorfia.

Não foi possível identificar os condicionamentos dos alomorfes do morfema causativo-comitativo em Kaiowá e em Guajajára, entretanto chama a atenção a correspondência desses alomorfes e a distribuição dos mesmos em duas línguas geograficamente tão distantes. Há a possibilidade de que haja uma variedade de alomorfes do morfema cognato em outras línguas Tupí-Guaraní e sua documentação é fundamental para o conhecimento e ensino dessas línguas nas escolas das aldeias. É necessário, portanto, que as descrições linguísticas que servem de base para a escrita dessas línguas considerem todos os alomorfes desses e dos demais morfemas das línguas, caso contrário podem, ao invés de contribuir para o fortalecimento do uso das línguas, reduzí-las, empobrecendo-as. 


\section{Referências}

Cardoso, V. Aspectos Morfossintáticos da Língua Kaiowá (Guarani). Tese de Doutorado. Campinas, SP: Unicamp. 2008.

Castro, Ricardo Campos. O epifenômeno da alternância de valência na língua Tenetehára (Tupí-Guaraní). Revista da ANPOLL, n. 34, p. 347-391, jan./jun. 2013.

Halle, Morris; Marantz, Alec. Distributed Morphology and the Pieces of Inflection. In:

Hale, Kenneth; Keyser, Samuel Jay. 1993. The View from Building 20. Cambridge: MIT Press, p. 111-176.

Harley, Heidi; Noyer, Rolf. Distributed morphology. Glot International, v. 4, n. 4, p. 3-9, 1999.

Harley, Heidi \& Rolf Noyer. 1998. Mixed nominalizations, short verb movement, and object shift in English. Proceedings of NELS 28, edited by Pius N. Tamanji and Kiyomo

Kusumoto, 143-157. Amherst: GLSA, University of Massachusetts, Amherst.

Harrison, Carl; Harrison, Carole. 2013. Associação Internacional de Linguística SIL Brasil Anápolis - GO.

Mejia, Blanca Flor Demenjour Munoz. 2017. Verbos em Kaiowá: uma descrição morfológica. Dissertação de Mestrado, Programa de Pós-Graduação em Letras, Universidade Federal da Grande Dourados.

Camargos, Q. F. 2017. Aplicativização, causativização e nominalização: uma análise unificada de estruturas argumentais em Tenetehára-Guajajára (Família TupíGuaraní). Tese de Doutorado, Universidade Federal de Minas Gerais.

Rodrigues, Aryon D. Morfologia do verbo tupi. Letras 1:121-152. Curitiba, 1953.

Rodrigues, Aryon D. 1985. Relações internas na família lingüística Tupí-Guaraní. Revista de Antropologia, 27/28:33-53. São Paulo. 